\title{
CUIDADO À MULHER SOROPOSITIVA NO CICLO GRÁVIDO-PUERPERAL: PERCEPÇÕES DE ENFERMEIRAS ${ }^{1}$
}

\author{
THE CARE OF HIV POSITIVE PREGNANT WOMEN: PERCEPTIONS OF NURSES. \\ CUIDADOS A LA MUJER SOROPOSITIVA DURANTE EL CICLO GRÁVIDO-PUERPERAL: \\ PERCEPCIONES DE ENFERMERAS
}

Débora Fernandes Coelho²

Maria da Graça Corso da Motta ${ }^{3}$

\begin{abstract}
RESUMO: O presente estudo tem por objetivo conhecer as percepções de enfermeiras, atuantes na área de Saúde da Mulher, sobre o cuidado realizado à mulher HIV+ no ciclo grávido-puerperal. Trata-se de um estudo exploratório com uma abordagem qualitativa. Foram participantes do estudo oito enfermeiras que atuam no ambulatório, centro obstétrico e internação obstétrica do Hospital de Clínicas de Porto Alegre. As informações foram coletadas através de entrevistas semi-estruturadas e submetidas à análise de conteúdo temático proposta por Minayo (1996). Os temas encontrados foram: Cuidado Humano: prática profissional; Dualidades - HIV X Cuidado e Ser Mulher Portador do HIV: olhar da enfermagem. O estudo vem contribuir para reflexão dos profissionais que atuam com pacientes portadores do HIV acerca das estratégias para a integralidade do cuidado prestado, priorizando um cuidado multidisciplinar e continuo. Reforça-se a necessidade de respeito às individualidades de cada ser para que o objetivo seja atingido.
\end{abstract}

PALAVRAS-CHAVE: cuidado, mulher HIV+, maternidade, enfermagem

ABSTRACT: The present study has as its objective to identify the perceptions of nursing professionals, who work in the field of women's health, regarding the care of HIV positive pregnant women. This is an exploratory study with a qualitative approach. The participants of the study were eight nurses who work in the obstetric clinic of Hospital de Clinicas in Porto Alegre. Data were collected through semi-structured interviews, which were analyzed according tothe theme content proposal of Minayo (1996). The themes identified in the interview were human care, professional practice, duality - HIV X Care and being an HIV positive women: the view of nursing. The study motivates professionals who care for HIV positive patients to reflect on strategies for a multidisciplinary and continuous care. It also emphasizes the importance of respecting individuals so that the objective can be achieved. KEYWORDS: care, HIV positive woman, maternity, nursing

RESUMEN: El presente estudio tiene por objetivo conocer las percepciones de las enfermeras que actúan con la Salud de la Mujer, sobre el cuidado que se les da a las mujeres con HIV + durante el ciclo del embarazo. Se trata de un estudio exploratorio con enfoque cualitativo. Participaron del estudio ocho enfermeras que actúan en el ambulatorio, centro obstétrico e internación obstétrica del Hospital de Clínicas de Porto Alegre. Se recogieron las informaciones mediante entrevistas semiestructuradas y sometidas al análisis de contenido temático propuesto por Minayo (1996). Los temas encontrados fueron: Cuidado Humano: práctica profesional; Dualidades -HIV \& Cuidado y Ser Mujer Portadora deI Sida: Ia mirada de enfermería. El estudio contribuye a la reflexión de los profesionales que actúan con pacientes del Sida, buscan estrategias para la integralidad del cuidado prestado y priorizan un cuidado multidisciplinario y continuo. Se refuerza la necesidad de respeto a las individualidades de cada ser para que el objetivo sea alcanzado.

PALABRAS CLAVE: cuidado, mujer HIV+, maternidad, enfermeria

Recebido em 12/09/2001

Aprovado em 18/12/2001

\footnotetext{
1 Trabalho de Conclusão do Curso de Graduação da Escola de Enfermagem da Universidade Federal do Rio Grande do Sul.

${ }^{2}$ Enfermeira. Mestranda do Curso de Mestrado em Enfermagem da Escola de Enfermagem da Universidade Federal do Rio Grande do Sul.

${ }^{3}$ Enfermeira, Doutora em Enfermagem. Professor Titular do Departamento Materno-Infantil da Escola de Enfermagem da Universidade Federal do Rio Grande do Sul. Orientadora do trabalho.
} 


\section{INTRODUÇÃO}

Durante minha trajetória acadêmica um grupo especial de mulheres provocou-me inquietações relativas ao cuidado a elas dispensado - as mulheres infectadas pelo Virus da Imunodeficiência Adquirida (HIV). Mulheres que, ao estarem no ciclo grávidopuerperal, enfrentam, além de todas as transformações significativas desse periodo, o sofrimento da presença de um virus que tem por conseqüência a Síndrome da Imunodeficiência Adquirida (AIDS), doença sabidamente, letal. Não bastando isso, adiciona-se a efetiva possibilidade de transmissão do vírus para o seu filho, condenando-o igualmente à morte.

Essa temática vem inquietando-me e entendo que muito há de se investigar em relação à mulher HIV+, o que motivou a realização do presente estudo.

A relevância do trabalho é de proporcionar à enfermagem uma reflexão na definição das estratégias de cuidado a essa clientela contribuindo, assim, com os vazios de conhecimento ainda existentes: mulher $\mathrm{HIV}+\mathrm{e} o$ processo da maternidade.

Portanto, o estudo buscou aprofundar um tema atual e de relevância para o grupo materno-infantil e, a partir do conhecimento gerado, propor cuidados a estas mulheres com base em experiências relacionadas ao fenômeno de estudo, além de contribuir na formação profissional, proporcionando uma adequação da teoria à prática.

\section{HIVIAIDS, MULHERES E ENFERMAGEM: UM OLHAR NA LITERAT URA ACERCA DA TRÍADE}

No início dos anos 80 o Virus da Imunodeficiência Adquirida (HIV) passou a tomar notoriedade em nosso meio. Inicialmente, era chamado de "peste gay", visto encontrar-se disseminado nesse grupo. No entanto, com o passar do tempo, outros grupos apresentaram o vírus, sendo denominados de "grupos de risco", aumentando a discriminação às pessoas infectadas. Hoje, já não existem os "famosos grupos de risco", mas sim as "situações de risco" a que os individuos podem estar expostos (NASCIMENTO, 2000).

Sprinz et al. (1999) salientam que nos dias atuais somente pertencer a espécie humana é suficiente para poder infectar-se com o HIV. No entanto, existem pessoas expostas a maior risco, pois a transmissão do virus ocorre por via sexual ou sangüínea.

Fazendo o contraponto a essa afirmação, a FIOCRUZ (2001) destaca que os casos de AIDS continuam a aumentar entre as mulheres. Esse fato preocupa os profissionais de saúde, pois as mulheres correm o risco de tornarem-se o principal grupo infectado, visto que, em 1982, quando a doença foi constatada no Brasil não havia registros de mulheres infectadas. Este quadro modificou-se quando os casos começaram a aparecer: uma mulher para cada 18 homens. Atualmente, a proporção é de uma mulher portadora do virus para cada dois homens.

Segundo Sprinz (1999) a suscetibilidade de contaminação por via sexual é quatro vezes maior na mulher do que no homem e, na grande maioria dos casos, a infecção nas mulheres deve-se à via de transmissão heterossexual.

Para Spindola e Banic (1998) o aumento dos casos de mulheres infectadas é preocupante, porque, em sua maioria, são mulheres em idade fértil que podem gerar crianças portadoras do HIV. Reforçam ainda que esse crescimento na infecção é resultado da falta de informação sobre o vírus e suas formas de contaminação.

A publicação do Ministério da Saúde (BRASIL, 2001, p. 158) acerca da assistência à mulher portadora do HIV durante o parto e puerpério informa que atualmente no Brasil "mais de $90 \%$ dos casos de AIDS em crianças estão relacionados à transmissão do HIV da mãe para o filho". Portanto, considera-se o conjunto HIV e gestação uma situação de alto risco, que deve ser tratada.

O motivo fundamental do tema gestação e HIV ser abordado diz respeito:

à especial condição de discriminação social e preconceito que sofre a mulher HIV+ durante a gestação e o parto. Considerando que uma abordagem adequada e completa à mulher HIV+ durante o pré-natal, o parto e o puerpério é capaz de reduzir os riscos materno-infantis a niveis muito próximos a de gestantes não infectadas, a freqüência da condição, a possibilidade de intervenções efetivas e a necessidade de reverter a discriminação sofrida por essas mulheres, justificam essa decisão. (BRASIL, 2001, p.158)

Para Marin, Paiva e Barros (1991) cuidar de uma mulher grávida por si só já se caracteriza, em algumas situações, um motivo de preocupação. Prestar assistência a uma gestante HIV+ causa nas enfermeiras e profissionais de saúde, em geral, uma maior gama de tensão e preocupação.

Frente a este fato, as mesmas autoras dizem que "os enfermeiros que cuidam de pacientes soropositivas tornam-se alvos das conseqüências sociais que o medo da transmissão acarreta" (1991, p. 19).

Portanto, cuidar de uma mulher HIV + e grávida, parturiente ou puérpera estabelece "um grande desafio para competência básica do enfermeiro, para os valores pessoais e profissionais e mesmo para as convicções éticas" (MARIN; PAIVA; BARROS, 1991 p. 19). 


\section{QUESTÃO DE PESQUISA E OBJETIVO}

Frente aos questionamentos que emergem da minha prática acadêmica e dos aspectos abordados na literatura sobre o tema, o presente estudo tem como foco de investigação a seguinte questão de pesquisa: Qual a percepção das enfermeiras, que atuam na área de Saúde da Mulher, sobre o cuidado realizado às mulheres HIV+, no ciclo grávido-puerperal? objetivo:

Sendo assim, o presente estudo tem como

- Conhecer as percepções de enfermeiras, atuantes na área de Saúde da Mulher, sobre o cuidado realizado pela enfermagem à mulher $\mathrm{HIV}+$ no ciclo grávido-puerperal.

\section{CAMINHADA METODOLÓGICA}

\section{CARACTERIZAÇÃO DO ESTUDO}

O estudo é do tipo exploratório tendo como referencial metodológico a abordagem qualitativa. $A$ pesquisa qualitativa, segundo Minayo (1997, p.21) "trabalha com o universo de significados, motivações, aspirações, crenças, valores e atitudes, o que corresponde a um espaço mais profundo das relações, dos processos e dos fenômenos que não podem ser reduzidos à operacionalização de variáveis".

\section{CONTEXTO}

O contexto do estudo é o Ambulatório - Zona 6. Centro Obstétrico e Unidade de Internação Obstétrica do Hospital de Clínicas de Porto Alegre.

\section{PARTICIPANTES}

As participantes da pesquisa são oito profissionais enfermeiras que atuam no atendimento a mulheres $\mathrm{HIV+}$, nos diferentes momentos do ciclo grávido-puerperal, ou seja, mulheres em acompanhamento pré-natal, parturientes e puérperas.

A escolha das enfermeiras foi feita através de sorteio. A fim de assegurar o anonimato das participantes foram estabelecidos nomes de personagens da literatura brasileira para cada uma.

\section{COLETA DAS INFORMAÇÕES}

A coleta das informações foi obtida por meio de entrevistas semi-estrutruradas com roteiro de questões relacionadas ao foco do estudo. Triviños (1987, p. 145) entende por entrevista semi-estruturada aquela que "parte de certos questionamentos básicos, apoiados em teorias e hipóteses, que interessam à pesquisa, e que, em seguida, oferecem amplo campo de interrogativas, fruto de novas hipóteses que vão surgindo à medida que se recebem as respostas do informante".

\section{CONSIDERAÇÕES BIOÉTICAS}

O projeto de pesquisa foi encaminhado à Comissão da Disciplina Estágio Curricular da Escola de Enfermagem da Universidade Federal do Rio Grande do Sul e, após aprovação, encaminhado à Comissão de Pesquisa e Ética em Saúde do Grupo de Pesquisa e Pós-Graduação (GPPG) do Hospital de Clínicas de Porto Alegre, tendo sido aprovado para o seu desenvolvimento.

A concordância da entrevistada em participar do estudo foi obtida através de um Termo de Consentimento Informado contendo esclarecimentos sobre: o objetivo do estudo, o papel do pesquisador na instituição, segurança ao anonimato, o caráter sigiloso das informações, o direito de não participação em qualquer momento e a garantia de destruição das fitas gravadas após sua transcrição.

\section{ANÁLISE DAS INFORMAÇÕES}

Para análise das informações coletadas foi utilizado o método de Análise de Conteúdo tipo Temático proposto por Minayo (1996). Esse método divide-se em três fases definidas: pré-análise, exploração do material e análise e interpretação das informações.

Portanto, na primeira fase, após a transcrição literal de todas as entrevistas, realizou-se recortes do texto com objetivo de delinear os temas para a análise temática. Ainda nesta fase, foi realizado uma organização das falas.

Na fase de Exploração do Material foi realizada várias releituras e agrupamentos das idéias iniciais emergindo temas e sub-temas.

\section{INTERPRETAÇÃO DAS INFORMAÇÕES}

A partir da análise das falas das enfermeiras, emergiram três temas distintos: Cuidado Humano prática profissional, Dualidades - HIV x Cuidado e Ser Mulher Portadora do HIV - olhar da enfermagem.

\section{CUIDADO HUMANO: PRÁTICA PROFISSIONAL}

Ao serem questionadas sobre o cuidado por elas prestado à mulher HIV+ as enfermeiras revelam uma diversidade de condutas relacionadas à prática de enfermagem. Assim, do tema apresentado emergiram quatro sub-temas: responsabilidades e estratégias do cuidado; importância das orientações: preocupações e deficiências no cuidado; evolução 
científica: ganhos no cuidado e medo do contágio auto-cuidado.

\section{- Responsabilidades e estratégias do cuidado}

Nas falas das participantes evidencia-se um senso de responsabilidade muito grande em desempenhar o cuidado à mulher HIV + no ciclo grávidopuerperal, principalmente, no que diz respeito à forma de comunicação usada para o seu desempenho, visto que a enfermeira, através de seu processo de trabalho, usa a comunicação como uma de suas principais ferramentas no estabelecimento de sua prática.

Acho que nós, muitas vezes, esquecemos que existe no nosso cotidiano a comunicação não verbal, aquela que através dos nossos gestos, nosso olhar. Até mesmo nossas mãos comunicam muitas coisas e as pacientes, ainda mais essas, que encontram-se mais vulneráveis, estão muito atentas a isso (Gabriela).

Ferraz, Alves e Peixoto (1995, p.21) consideram a comunicação em enfermagem como "relacionamento, interação, comportamento verbal, veículo de informação a pacientes, instrumento terapêutico, instrumento básico da enfermagem, dentre outros". Evidenciando-se, então, uma grande diversidade de abordagens para a comunicação em enfermagem.

No entanto, Mendes et al. (1991) dizem que se a enfermagem pretende continuar com seu papel expressivo, como prioridade de sua prática profissional, a equipe deve estar atenta para diminuir o temor, a angústia, a perturbação, devendo saber ouvir e estimulando o paciente a expor seus sentimentos, ajundando-o.

As enfermeiras deixam evidente que o cuidado à mulher HIV+ tem como responsabilidade permitir um cuidado livre de julgamentos e de avaliações sobre estilos de vida, deixando claro que esse tipo de conduta não deve fazer parte do relacionamento, pois não representa nenhum beneficio à paciente.

Sempre me coloco no lugar da paciente e sinto que pra elas está sendo muito difícil e, que às vezes, tornamos mais difícil ainda através da assistência prestada. Não estamos aqui para julgar comportamento, estilo de vida, estamos aqui para cuidar, transmitir conhecimento para que as coisas da vida se tornem mais fáceis (Ana Terra).

Para Randünz (1998) ao definir enfermagem como o cuidar do ser humano, refere-se sobre a dignidade que deve-se ter com o outro nesse desempenho, e essa vem representada pelo respeito durante o processo de vida de cada ser que venha a necessitar de cuidado.

Segundo Marin, Paiva e Barros (1991) o diagnóstico HIV+ estabelece, na maioria das vezes, um julgamento moral sobre o portador, passando a ser classificado como um ser carente de boas qualidades. Para a mulher gestante, ao saber-se portadora, cria-se a necessidade de redefinir-se quanto a sua própria vida e junto está sempre presente o medo da rejeição, do abandono, a necessidade em manter a própria dignidade.

Através da fala de uma participante fica nitida a importância do cuidado qualificado da equipe de saúde para definição do processo da maternidade na vida de uma mulher infectada e a responsabilidade da enfermagem como membro dessa equipe.

Se ela já vinha com o tratamento, agora depende de nós fazer com essa coisa se defina, porque o momento de maior risco é no parto (Ana Terra).

Segundo o Manual de recomendações para profilaxia da transmissão materno-infantil do HIV e terapia anti-retroviral em gestantes (BRASIL, 2001b, p.10) "as rotinas de diagnóstico e de assistência prevêem medidas bastante eficazes no diagnóstico precoce e controle da infecção materna e de terapêutica profilática da transmissão materno-infantil". Desse modo, quando ocorre a transmissão vertical, demonstra-se falhas no sistema de saúde.

A preconização de uma abordagem adequada para a mulher HIV + durante o pré-natal, o parto e o puerpério é apontada para a redução dos riscos materno-infantis a niveis muito próximos aos de gestantes não portadoras (BRASIL,2001a).

No que diz respeito às estratégias utilizadas para a qualidade do cuidado desenvolvido, as enfermeiras enfatizam a necessidade de informação que a paciente requer para situar-se nesse processo, portanto acreditam que o profissional deve fazer com que essa paciente compreenda exatamente esse universo em que vive. A partir do momento que ocorre a verdadeira compreensão da paciente sobre seu estado, os resultados do cuidado ficam evidentes.

Tem que usar de estratégias adequando a comunicação e aí a gente sabe que a lógica minha como profissional do lado de cá da mesa e a lógica do paciente do outro lado da mesa, na maioria das vezes, é completamente diferente. Então, em primeiro lugar, é usar da estratégia de se dar conta que a comunicação tem que funcionar. Porque se a comunicação não funcionar, vai haver um ruído não vai haver uma interação boa entre o profissional e o paciente, porque o paciente não vai compreendere não vai conseguir se cuidar (Macabéia).

Para Langone e Vieira (1995, p.27) "o código simbólico-lingüistico usado para veicular a informação deve privilegiar a todos. A informação deve estar adequada a caracteristicas especificas, levando em 
consideração o meio cultural e sócio-econômico na elaboração da mensagem simbólica".

Fica evidente que a humanização do atendimento em saúde gira em torno do reconhecimento das individualidades de cada um. $\bigcirc$ profissional de saúde deve estabelecer um vínculo com cada mulher, percebendo, assim, suas necessidades e capacidade em enfrentar o processo de maternidade (BRASIL, 2001a).

IMPORTÂNCIA DAS ORIENTAÇÕES: PREOCUPAÇÕES E DEFICIÊNCIAS NO CUIDADO

As enfermeiras relatam que consideram a orientação um dos principais focos a ser trabalhado para a eficiência do cuidado prestado. Sabe-se que a enfermeira possui caracteristicas educadoras no desempenho de sua prática, trabalhando na dimensão de educação para a saúde. Percebe-se uma preocupação em desempenhar esse papel educador, colocando-o como um fator diferencial de seu exercicio profissional.

A orientação é a base, porque se ela não assimilar essa questão da importância do cuidado com ela e o bebê, não tem porque a gente estar aqui, senão a gente bota umas máquinas de executar tarefas e acabou (Helena).

De acordo com Langone e Vieira (1995) orientações sobre possibilidades de tratamento e prevenção auxiliam a pessoa portadora do vírus, reduzindo a ansiedade e o desconhecimento sobre as dificuldades do processo. Sendo assim, a paciente não permanece sem apoio, com medo das alterações de saúde que possam surgir.

Através das colocações das entrevistadas percebe-se uma preocupação com as orientações acerca das dificuldades que possam vir a surgir devido às características peculiares da mulher HIV+ no processo de maternidade. $O$ fato dessa mulher não poder amamentar gera, na maioria das entrevistadas, uma tendência em enfatizar o cuidado para que não surjam intercorrências durante esse período.

Essas orientações estão presentes tanto os cuidados com a própria mulher, como nos cuidados necessários ao recém-nascido, portanto orienta-se de forma conjugada os cuidados a essa dupla. $O$ grande centro das orientações parte da premissa que devese, de todas as maneiras, reduzir, ao máximo, as chances da transmissão vertical do vírus da mãe para filho.

Minha preocupação com relação a ela é como saber lidar com as mamas. É orientar o que ela deve fazer para não ter desconforto, saber que o nenê não pode mamar e, que por isso, podem ter a mama ingurgitada, apresentando dor, febre, problemas que possam virporcausa da mama ingurgitada. Ė orientar ela com relação a esse cuidado das mamas (Capitu).

Tem a questão do $A Z T$, a gente faz o AZTEV, orienta-se que é para proteção do bebê fazer na hora do nascimento, que depois o nenê vai receber também, a $m$ amadeira e tal (Gabriela).

Segundo Teixeira et al. (1999) as orientações/ informações devem ser transmitidas em várias etapas e não em um único encontro, facilitando a compreensão.

Concordo com Langone e Vieira (1995) quando dizem que existe a necessidade da elaboração de mensagens claras na área da educação em saúde, facilitando a compreensão de pessoas pertencentes a diferentes niveis sócio-culturais.

A publicação BRASIL (2001a) salienta que deve-se inibir a lactação da puérpera, logo, após o parto. Esta inibição pode ser conseguida com a compressão das mamas com atadura. Além disso, recomenda-se o uso de medicação específica para esse fim. Reforça, ainda, a importância do apoio da equipe de saúde a essa mulher, para que não se sinta discriminada por não amamentar.

A partir dos depoimentos evidencia-se que a amamentação é um fator gerador de dificuldades e deficiências no cuidado prestado pela enfermeira.

Percebe-se, através das falas, que as enfermeiras possuem dificuldades, em alguns momentos, em orientá-la, no entanto, essas são superadas pela vontade de que essa orientação sirva para a harmonia da mulher e seu bebê.

Às vezes fica bem confuso, em alguns momentos tenho que parar e pensar antes de entrar nos quartos, pois a pergunta básica é entrar e perguntar e aí, o bebê mamou bem? Tá sugando direitinho? E quando é HIV tem que perguntar se aceitou bem o complemento, se não está rejeitando, como está sendo (Iracema).

A única coisa difícil é orientar duas coisas completamente opostas. Às vezes fico no meio de duas macas, de um lado HIV, do outro uma mulher não infectada, e tenho que mudar o discurso quase que automático, só dá tempo de puxar o ar e virar (Bibiana).

Durante minha trajetória acadêmica, pude constatar que existe um grande estímulo do meio científico e do meio popular para o aleitamento materno, devido ao benefício que este ato proporciona à mãe e ao bebê. Nesse sentido, criamos uma imagem de maternidade muita arraigada à imagem do aleitamento materno. Por isso, percebo uma grande dificuldade ao tratarmos mulheres que não podem desempenhá-lo, pois estariam causando prejuizos ao seu bebê. Acredito que não estimular o aleitamento materno causa uma sensação de vazio, culpa e impotência no desempenho do cuidado. 
A publicação do Ministério da Saúde (BRASIL, 2001a, p.143) reforça a importância desse ato relatando que "o aleitamento materno é, atualmente, considerado peça fundamental para a saúde materna e perinatal e, portanto, faz parte das estratégias de todos os programas relacionados com estes objetivos".

Não obstante, Langone e Vieira (1995) relatam que existem dificuldades para o desenvolvimento da relação terapêutica. O profissional de saúde também é o centro da abordagem, portanto está sujeito a altos niveis de stress como o cliente. Esse é passivel de erros como qualquer ser humano, que possui uma carga cultural, estabelecida por conhecimentos adquiridos e por seus próprios valores e crenças.

Algumas profissionais relatam deficiências em realizar um cuidado integral à paciente e seu bebê. Revelam um descompasso entre as equipes no desenvolvimento da assistência e, também, uma carência na integralidade do cuidado.

Elas normalmente não têm recebido a medicação para inibir a lactação, a equipe médica não tem prescrito, é muito raro elas terem essa prescrição e, às vezes, elas já saem com a mama enchendo ou cheia. Dizem que existem muitos efeitos colaterais, que o benefício seria menor que os malefícios em prescreve-la, mas recebemos uma circular da Secretaria da Saúde determinando o uso, que é importante o uso. Já passamos para eles, mas não mudaram a conduta, parece que cada vez menos estão usando. Eu fico com pena, porque é um problema a mais que elas vão ter. Já que a Secretaria de Saúde está indicando, acredito que os malefícios não sejam tão grandes assim (Capitu).

O estudo realizado por Vermelho, Barbosa e Nogueira (1999) sobre mulheres com AIDS relata que a infecção das mulheres e seu adoecimento têm uma perspectiva difícil. Reforçam que "é histórico em nosso país que a assistência à saúde da mulher é postergada, sendo o diagnóstico e a assistência mais tardios, a avaliação inadequada, pouca pesquisa dirigida, entre outras questões" (1999, p.3).

\section{- Evolução científica: ganhos no cuidado}

As entrevistadas reconhecem que o desenvolvimento de um cuidado de qualidade depende dos resultados de estudos científicos na área do HIV, pois salientam que os avanços da ciência no tratamento de pacientes portadores do virus foram fatores facilitadores da prática desse cuidado. Reforçam a evolução sofrida nos últimos anos desde os primeiros casos, enfocando os benefícios adquiridos.

"Eu acho que está desmistificando a questão da paciente ser HIV. Acho que antigamente era uma questão mais acobertada, a preocupação era bem maior, hoje sabemos lidar com mais tranqüilidade, isso vemos com a evolução da coisa. Já fazem mais de dez anos, e no começo era muito complicado, nos amedrontávamos muito, porque não tinham muitos estudos, parecia que pegávamos as coisas pelo ar. Amadurecemos muito nessa questão científica" (Ana Terra).

"Eu considero um dos maiores "booms" da história da AIDS o protocolo 076. É tu teres a possibilidade de fazer prevenção de uma doença para esse feto. Então, eu poder cuidar de uma grávida infectada pelo HIV ensinando ela que existe alguma maneira dela pensar em não passar esse vírus para seu filho, se ja durante o pré-natal, durante a gestação, seja transparto ou seja não amamentando o bebê e cuidando do bebê no puerpério, sabendo previamente ao nascimento que vai ter que usar o xarope de $A Z T$ e é dessa forma que se cuida, para mim é uma grande satisfação" (Macabéia).

Ao identificar o progresso da ciência no que diz respeito ao HIV Lobato e Zaché (2001) relatam que nos dias atuais existem no mundo vários estudos que avaliam os tratamentos em seres humanos em busca da cura, demonstrando um número significativo e confortante, visto que há dez anos atrás existiam apenas cerca de dez trabalhos. Seguem nessa linha de pensamento dizendo que a medicina tem comemorado os progressos no tratamento da doença, com uma variedade cada vez maior de intervenções para o controle da doença. Portanto, o tratamento da AID não apenas controla o vírus como oferece a possibilidade de o paciente viver melhor.

Sabe-se que hoje o diagnóstico da infecção do HIV na mulher durante o pré-natal contribui para a redução da probabilidade de transmissão do vírus da mãe para o feto. O Brasil, com base no Protocolo 076 do Aids Clinical Trial Group (PACTG 076) vem desde 1994 disponibilizando para as gestantes portadoras do HIV o AZT oral, desde 1996, o AZT injetável quando parturiente e o AZT solução oral para os recémnascidos. Segundo estudos, o uso dos anti-retrovirais é capaz de reduzir significativamente a carga viral do HIV para niveis indetectáveis, levando as taxas de transmissão materno-infantil para niveis inferiores a 3\% (BRASIL, 2001b).

\section{- Medo do Contágio - Auto-Cuidado}

Constata-se através dos relatos das participantes um temor, mesmo que velado e discreto, sobre o medo de contágio do HIV ao contato direto com essa paciente. As precauções utilizadas no contato direto com as pacientes são verbalizadas no decorrer das entrevistas.

Mesmo tendo a precaução universal, a gente tem só mais um pouco de cuidado com a paciente 
HIV, com essa questão de transmissão, contaminação, afinal de contas, o sangue é o que contamina e, na nossa área, ele aparece muito, ela ta muito presente (Gabriela).

Claro que, como é uma doença, ela é portadora de um vírus que pode ser transmitido, agente tem algumas precauções. No caso da gestante, só quando ela tiver bolsa rota ou alguma coisa que nos faça ter mais contato com fluídos, se não o relacionamento, a manipulação da paciente é igual a qualquer outra. Cuidados com sangues e fluídos. Na puérpera também (Helena).

Segundo Teixeira et al. (1999) constata-se um nivel de desconforto dos profissionais de enfermagem em cuidar de pacientes HIV pelo medo de contaminação, visto que o risco de contágio é de aproximadamente $0,3 \%$ após um acidente de trabalho.

\section{DUALIDADES - HIV X CUIDADO}

Durante os relatos das profissionais percebeuse o estabelecimento de alguns conflitos enfrentados no dia-a-dia no desempenho do cuidado às mulheres portadoras do HIV, decorrentes das particularidades que existem em relação a essa paciente. Portanto surgiram nesse tema um sub-tema: Proteção $X$ Discriminação.

\section{- Proteção X Discriminação}

A partir dos relatos das participantes fica evidente a dificuldade que ainda há entre os profissionais de saúde no seu relacionamento com a paciente HIV+ no processo de maternidade.

Portanto, constata-se que a equipe de saúde tem plenas condições de, ao invés de proporcionar à paciente um ambiente acolhedor e protetor, um ambiente ameaçador e constrangedor, através da forma que trabalha seus valores e suas crenças.

"Proteger a paciente, não discriminar. Porque sabemos que a discriminação existe, dentro da própria familia elas estão sofrendo essa discriminação. Eu considero que a equipe de saúde ainda discrimina muito ela" (Capitu).

Eu gostaria que todo mundo as tratasse não diferenciadas, porque elas se sentem diferenciadas. Algumas escondem ser HIV pelo medo de ser tratada diferente, então que todo mundo as trate iguais (Bibiana).

Na prática diária percebo muita hostilidade da equipe em lidar com ela, existe muito preconceito nas entre linhas (Ana Terra).

Para Sadala (2000), o preconceito existente sobre os problemas envolvidos com a AIDS, leva o profissional da saúde a expressar rejeição às pessoas $\mathrm{HIV}+$.

A mesma autora aponta a existência de uma discriminação aos portadores do HIV pelos profissionais de saúde e pelo sistema de saúde, caracterizando um desrespeito aos seus direitos de cidadão, tanto nos aspectos sociais e legais quanto nos éticos e morais.

De acordo com Marin, Paiva e Barros (1991) por se tratar de um vírus vinculado à sexualidade, algumas mulheres, escondem serem portadoras, por medo ou vergonha de exporem à sociedade.

Fica evidente nas falas que o preconceito é manifestado durante o cuidado à paciente, interferindo na qualidade do atendimento.

Sei que somos humanos, que temos o direito de sentirmos tudo que nos acontece, mas, em algumas situações, não controlamos e podemos estar causando um dano maior ao paciente (Ana Terra).

A dor do preconceito, às vezes, é muito maior que a dor física, e nós podemos, muito facilmente, provocar essa dor. Infelizmente é assim (Gabriela).

Concordo com Padoim (1999) que o preconceito está presente em muitas das atitudes na prática do cuidado de enfermagem, sendo manifestado pelo comportamento discriminatório, medo, insegurança e desconhecimento.

Para Vermelho, Barbosa e Nogueira (1999) a resposta social à AIDS é reconhecimento de rejeição, através do pânico e preconceito. Embora os meios de comunicação discutam bastante o tema, o que se percebe nos serviços de saúde é a desinformação e o despreparo de seus profissionais para lidar com o problema.

\section{SER MULHER PORTADORA DO HIV: OLHAR DA ENFERMAGEM}

A partir das colocações das enfermeiras no decorrer das entrevistas, estabeleceu-se algumas percepções sobre a mulher HIV+ no ciclo grávidopuerperal. Assim, surgiram dois sub-temas: O ser mulher/paciente e percepções da maternidade.

\section{- O ser mulher/paciente}

De acordo com as falas das enfermeiras, fica evidente a percepção imediata de normalidade dessa paciente, deixando claro que percebem essa mulher como uma paciente igual às outras, necessitando de cuidados. No entanto, ao passo que vão discorrendo sobre o assunto, demonstram uma diferenciação devido à presença do virus associado ao periodo de maternidade. Fica claro nos relatos que existe um comprometimento da enfermagem em tratar essa 
paciente da forma mais humanizada possivel.

No aspecto geral, como pessoa, eu considero ela igual às outras pacientes (Capitu).

Eu não faço diferença com nenhuma (Iracema).

Não vejo a paciente com o HIV e sim uma paciente grávida que precisa de minha ajuda (Bibiana).

Na verdade, não há diferença, ela é uma paciente que está ali com as mesmas angústias de uma mãe que vem ter o seu filho (Gabriela).

As mesmas participantes relatam após um determinado tempo as diferenças.

O que faz a diferença é a preocupação com essa situação dela de ser portadora do HIV e do seu bebê. Devemos dar maior atenção para esse aspecto (Capitu).

A diferença está em essa mulher ser infectada e acrescentada a maternidade (Iracema).

Uma mulher que precisa de uma medicação especial, porisso, ela é diferente (Bibiana).

Para mim, não é que ela seja complicada, mas ela é diferente (Gabriela)

O estudo realizado por Sadala (2000) com profissionais de saúde sobre o cuidar de pacientes com AIDS evidencia que vários profissionais reforçam a igualdade, não apresentando motivos para uma assistência diferenciada. Relatam que todos os doentes são iguais, as doenças contagiosas são iguais, nada as diferenciam. Porém, a forma como o dizem assume uma posição defensiva, como se o estabelecido fosse a "diferença" desse paciente. Fica evidente a necessidade em reafirmar a igualdade, porque ela é a todo tempo negada.

\section{- Percepções da maternidade}

Em determinadas falas notou-se a preocupação das enfermeiras em justificar o porquê da busca da maternidade pelas mulheres portadoras do HIV. Evidencia-se que a forma como percebem esse processo na vida dessa mulher, incentiva, ainda mais, a preocupação em desenvolver um cuidado de excelência para essa paciente.

Para mim elas engravidam, pois é uma maneira de continuarem a vida delas, é uma esperança, a cada filho que ela tem, é uma maneira de pensarque aquele ali pode negativar e pode dar continuidade a vida dela. A possibilidade de viverem nesses filhos (Anita).

Segundo Spindola e Banic (1998) a partir dos resultados de sua pesquisa sobre o ser mãe portadora do HIV, relatam que as mulheres HIV+ encaram de maneira diferente a maternidade. Para algumas o fato de possuir o virus não interfere no deslumbramento que o nascimento de um bebê proporciona. Para outras, este momento é percebido com tristeza, dúvidas, receios e preocupação com o futuro dela e de seu bebê.

Reforçam que ser mãe portadora do HIV é vivenciado como um momento de reflexão sobre o futuro. Assim, é o futuro que baseia os pensamentos dessas mulheres, como se o presente não existisse. A esperança de cura é uma constante no pensamento delas.

\section{CONSIDERAÇÕES FINAIS}

O estudo vislumbra a importância real da profissional enfermeira no processo de maternidade da mulher HIV+. Ficam evidentes as lacunas ainda existentes no desempenho do cuidado a essas pacientes, no entanto ressalta-se a busca constante de conhecimento pelas enfermeiras, a fim de estarem sempre atualizadas. Evidencia-se claramente a consonância entre a evolução cientifica e as facilidades adquiridas para o desempenho da prática profissional. As participantes do estudo concordam com os ganhos advindos da evolução científica no decorrer dos anos frente ao tratamento de pacientes HIV+.

As principais estratégias de cuidado utilizadas na prática diária das enfermeiras permeiam em torno da proteção da criança que a paciente HIV+ está gerando. Existe uma estreita relação com o cuidado prestado e os resultados positivos acerca da existência dessa criança saudável em nosso meio, portanto as enfermeiras possuem, intrinsecamente, uma responsabilidade no sucesso da vida dessa criança. Por outro lado, se não houver uma interação eficaz com outros membros da equipe multidisciplinar, o sucesso ficará comprometido, visto que a enfermeira como ser único não possui autonomia suficiente para contemplar todas as necessidades da paciente e seu filho.

A partir das percepções de cuidado advindas das enfermeiras do estudo, trago como referencial a definição de cuidar profissionalmente de Randünz (1998, p.15) que assemelha-se às idéias das informações subjetivas coletadas nessa pesquisa:

Cuidar profissionalmente ou cuidar em enfermagem é olhar enxergando o outro, é ouvir escutando o outro; observar, percebendo o outro, sentir, empatizando com o outro, estando disponivel para fazer com ou para o outro aqueles procedimentos técnicos que ele não aprendeu a executar ou não consegue executar, procurando compartilhar o saber com o cliente e/ou familiares a respeito, sempre que houver interesse e/ou condições para tal. Ao cuidar, procurar-se-á estabelecer também uma política assistencial de saúde e de enfermagem, garantindo acesso ao tratamento, à medicação, etc..., o que certamente, 
garantirá uma qualidade da assistência.

O estudo mostra a importância em conhecer as percepções de enfermeiras acerca de um cuidado desenvolvido, pois, a partir desse conhecimento, abrese um leque de possibilidades para a melhora e o aperfeiçoamento da prática. Apesar de não tratar-se de um estudo avaliativo, este possibilita uma reflexão dos atores sobre o papel que vêm desempenhando, proporcionando momentos de crítica e auto-critica para os envolvidos.

O estudo vem contribuir para reflexão dos profissionais que atuam com pacientes portadores do HIV acerca das estratégias para a integralidade do cuidado prestado, priorizando um cuidado multidisciplinar e contínuo. Reforça-se a necessidade de respeito às individualidades de cada ser para que o objetivo seja atingido.

Portanto, fica evidente a necessidade de um cuidado integral e humanizado para as pacientes HIV+ no ciclo grávido-puerperal, a fim de que possamos amenizar, ao máximo, as dificuldades enfrentadas por elas nesse periodo peculiar de sua existência, a maternidade associada à presença de um virus que tem como conseqüência uma doença, com prognóstico muito reservado.

\section{REFERÊNCIAS BIBLIOGRÁFICAS}

BRASIL. Ministério da Saúde. Parto, aborto e puerpério - assistência humanizada à mulher. Brasilia: Ministério da Saúde, 2001a.

BRASIL, Ministério da Saúde. Recomendações para profilaxia da transmissão materno-infantil do HIV e terapia anti-retroviral em gestantes. Brasilia: Ministério da Saúde, 2001b.

FERRAZ, A.F.; ALVES, M.; PEIXOTO, M.R.B. Comunicação terapêutica na prática profissional e social do enfermeiro. Revista Gaúcha de Enfermagem, Porto Alegre, v. 16, n.1/ 2, p. 21-29, jan./dez. 1995.

FIOCRUZ, Programa Radis. Mulheres, Casadas e com AIDS. Revista Súmula, Rio de Janeiro, n. 82, jun. 2001.

LANGONE, A.; VIEIRA, N. SIDA/AIDS: ação integrada como receita de vida - portador, familia, profissional, governo e sociedade. Porto Alegre: AGE, 1995.

LOBATO, E.; ZACHÉ, J. Dose de esperança: a ciência progride no desenvolvimento de vacinas preventivas contra o HIV e a medicina garante melhor qualidade de vida aos pacientes com AIDS. Revista Isto É, São Paulo, n. 1676, p. 76-79, 14 de nov. 2001.

MARIN, H.F; PAIVA, M.S; BARROS, S. M.O. AIDS e Enfermagem Obstétrica. São Paulo: Editora Pedagógica e Universitária, 1991.

MENDES, I.A.C. et al. Comunicação com o paciente: o teórico e o concreto na enfermagem de âmbito hospitalar. Revista Brasileira de Enfermagem, Brasilia, v.44, n. 2/3, p.98-102, abr/set.1991.

MINAYO, M. C. de S. O desafio do conhecimento: pesquisa qualitativa em saúde. 4.ed. São Paulo - Rio de Janeiro: Hucitec - Abrasco, 1996.

Pesquisa social: teoria, método e criatividade. 7 . ed. Petrópolis: Vozes, 1997.

NASCIMENTO, D.R. A AIDS no Final do Século. In: CONGRESSO BRASILEIRO DE SAÚDE COLETIVA, 6. Salvador, 2000. Anais... Salvador: Abrasco, 2000. 1 CDROM.

PADOIN, S.M.M.. Em busca do estar melhor do serfamiliar e do ser-com AIDS. In: PROCHNOW, A.G.; PADOIN, S.M.M.; CARVALHO, V.L. Diabetes e AIDS: a busca do estar melhor pelo cuidado de enfermagem. Santa Maria: Pallotti, 1999.

RANDÜNZ, V. Cuidando e se cuidando: fortalecendo o self do cliente oncológico e o self da enfermeira. Goiânia: AB, 1998.

SPINDOLA, T.; BANIC, M. Ser mãe portadora do HIV análise compreensiva. Revista de Enfermagem da Escola Anna Nery, Rio de Janeiro, v.2, n1/2, p. 101 - 109, abr./set. 1998.

SPRINZ, E. et al. Rotinas em HIV e AIDS. Porto Alegre: Artes Médicas, 1999.

TEIXEIRA, A.B. et al. Cuidados de Enfermagem. In: SPRINZ, E. et al. Rotinas em HIV e AIDS. Porto Alegre: Artes Médicas, 1999.

TRIVIÑOS, A.N.S. Introdução à pesquisa em ciências sociais: a pesquisa qualitativa em educação. São Paulo: Atlas, 1987.

VERMELHO, L.L; BARBOSA, R.H.S; NOGUEIRA, S.A. Mulheres com AIDS: desvendando histórias de risco. Cadernos de Saúde Pública, Rio de Janeiro, v. 15, n. 2, p. 1-18, abr./jun. 1999. 